\title{
Prevalência e fatores de risco associados à infecção pelo herpesvírus bovino tipo 1 em rebanhos bovinos leiteiros no estado do Maranhão
}

\section{Prevalence and risk factors associated with infection by bovine herpesvirus type 1 in dairy cattle in the state of Maranhão}

\author{
Danilo Cutrim Bezerra,${ }^{*}$ Nancyleni Pinto Chaves, ${ }^{* *}$ Vanessa Evangelista de Sousa, ${ }^{* * *}$ Hamilton Pereira Santos, ${ }^{* * *}$ \\ Hélder de Morais Perreira***
}

\begin{abstract}
Resumo
O presente estudo teve como objetivo determinar a prevalência e os fatores de risco para a infecção pelo herpesvírus bovino tipo 1 (BoHV-1) em fêmeas bovinas leiteiras no estado do Maranhão. Amostras de soro de animais não vacinados contra o BoHV-1 e provenientes de 92 propriedades foram submetidas à técnica de ELISA indireto. Em cada propriedade avaliada, aplicou-se ainda um questionário epidemiológico para investigar os fatores de risco que poderiam estar associados à infecção pelo vírus. As amostras foram coletadas de animais que apresentavam sinais clínicos sugestivos para a infecção, como sinais respiratórios e reprodutivos ou de animais sem sinais clínicos da infecção pelo vírus. Das 920 amostras de soro analisadas, $71,30 \%$ ( $\mathrm{n}=656$ ) foram reagentes pelo ELISA, sendo que $100 \%$ das propriedades apresentou pelo menos um animal positivo. Dentre os fatores de risco avaliados, faixa etária entre 3 e 7 anos apresentou significância estatística $(P<0,05)$ associada à infecção pelo BoHV-1. Os resultados do estudo indicam que a prevalência de anticorpos contra o BoHV-1 foi elevada e, apenas a faixa etária esteve associada ao risco de infecção pelo BoHV-1.
\end{abstract}

Palavras-chave: BoHV-1, anticorpos, ELISA, vacas leiteiras, odds ratio.

\begin{abstract}
This study was performed in order to determine the prevalence of bovine herpesvirus 1 (BoHV-1), and the main factors related of the infection in dairy cows not vaccinated against BoHV-1 from state of Maranhão. Serum samples were submitted to an indirect ELISA test for detection of BoHV-1 antibodies. An epidemiological questionnaire was applied for each herd to investigate variables that could be associated with this infection. The samples were collected from animals with clinical signs suggestive of infection, such as reproductive and respiratory signs or animals without clinical signs of infection. Of the 920 serum samples analyzed, $71.30 \%$ $(n=656)$ were positive by ELISA, and $100 \%$ of the properties had at least one positive animal. Among the risk factors evaluated, aged 3-7 years showed statistical significance $(P<0.05)$ associated with BoHV-1. The study results indicate that the prevalence of antibodies against BoHV-1 was high and that only age was associated with risk of BoHV-1.
\end{abstract}

Keywords: BoHV-1, antibodies, ELISA, dairy cows, odds ratio

\section{Introdução}

Entre as principais causas de perdas na produtividade de bovinos leiteiros destaca-se a infecção causada pelo herpesvírus bovino tipo 1 (BoHV-1) (Frondoloso et al. 2008). A infecção pelo BoHV-1 pode resultar em uma grande variabilidade de sinais clínicos, associados à enfermidade respiratória, conhecida como rinotraqueíte infecciosa bovina (IBR), vulvovaginite pustular infecciosa (IPV), balanopostite pustular infecciosa (IPB), reabsorção embrionária, abortamento, infertilidade temporária, nascimento de animais fracos e infecção multissistêmica fatal dos neonatos (Muylkens et al. 2007).

Uma característica importante do BoHV-1 é a capacidade de estabelecer latência em gânglios de nervos sensoriais, principalmente os gânglios trigêmeo e sacral (Jones 2003).
A reativação viral pode ocorrer quando os animais são submetidos a fatores estressantes, que diminuem a resistência imunológica (Colodel et al., 2002), quando haverá reexcreção de partículas virais, sendo responsável pela manutenção do vírus no rebanho (Vieira et al., 2003, Vogel et al., 2003). Uma vez infectado, o animal será portador e fonte de infecção por toda vida, assegurando a permanência do vírus na população bovina (Jones, 2003).

O BoHV-1 é um patógeno de distribuição mundial, com exceção de alguns países europeus que erradicaram a infecção (Ackermann e Engels, 2006, Cilento et al. 2011, Steukers et al., 2011). Vários relatos têm demonstrado que, no Brasil, este vírus está amplamente disseminado no rebanho bovino (Barbosa et al., 2005, Rissi et al., 2007, Silva et al., 2007, Holz et al., 2009).

\footnotetext{
* Doutorando em Biotecnologia, Rede de Biodiversidade e Biotecnologia da Amazônia Legal, BIONORTE, São Luís - MA.

** Doutoranda em Biotecnologia, Rede Nordeste de Biotecnologia, RENORBIO, São Luís - MA. Autor para correspondência: nancylenichaves@hotmail.com

*** Laboratório de Diagnóstico de Doenças Infecciosas, Universidade Estadual do Maranhão, Escola de Medicina Veterinária, São Luís - MA.
} 
O controle e erradicação da infecção pelo BoHV-1 baseia-se na identificação e remoção dos animais soropositivos (portadores da infecção latente), associados ou não ao uso de vacinas (Ackermann e Engels, 2006). O diagnóstico é realizado através da detecção do vírus ou componentes virais, ou mediante demonstração de anticorpos específicos em animais não vacinados (Vieira et al., 2003).

A identificação de fatores de risco associados à ocorrência de infecções por BoHV-1 em sistema intensivo de criação no Maranhão será importante para auxiliar a planificação de estratégias de controle fundamentada em estudos experimentais. Neste contexto, o trabalho teve o objetivo de determinar a prevalência de anticorpos e os fatores de risco potencialmente associados à infecção pelo BoHV-1.

\section{Material e métodos}

\section{População estudada}

Este estudo transversal foi realizado no estado do Maranhão, de acordo com o delineamento amostral desenvolvido no estudo soroepidemiológico da brucelose bovina no estado, no contexto do Programa Nacional de Controle e Erradicação da Brucelose e Tuberculose Bovina (PNCEBT). O estudo foi realizado na bacia leiteira do estado do Maranhão que é constituída pelas regionais da llha de São Luís (municípios de Paço do Lumiar, Raposa, São José de Ribamar e São Luís), Imperatriz (Amarante, Imperatriz, João Lisboa, Lageado Novo, Porto Franco, São João do Paraíso e Senador La Roque), Açailândia (municípios de Açailândia, Cidelândia e São Francisco do Brejão), Pedreiras (Bernardo do Mearim, Igarapé Grande, Pedreiras e Trizidela do Vale) e Bacabal (Bacabal, Bom Lugar, Lago Verde, Olho d'Água das Cunhas e São Luís Gonzaga).

\section{Delineamento amostral}

A amostragem foi realizada em duas etapas. Primeiro, foi feita a seleção aleatória de um número preestabelecido de propriedades, que representam as unidades primárias de amostragem. Dentro das unidades primárias, foi amostrado de forma aleatória um número preestabelecido de animais (unidades secundárias), com a finalidade de determinar o estado sanitário do rebanho.

O cálculo do número de rebanhos foi determinado pelo grau de confiança, nível de precisão desejado e pelo valor da prevalência (Sousa et al., 2009), utilizando-se a fórmula para amostras simples aleatórias, segundo Thrusfield (1995).

A seleção aleatória dos rebanhos, para cada regional, foi realizada a partir do cadastro de propriedades existentes junto à base da Unidade Veterinária Local de cada município da Agência Estadual de Defesa Agropecuária do Maranhão (AGED-MA). Para cada município, as propriedades existentes foram numeradas e os dados armazenados em planilhas do programa Microsoft Excel $2000^{\circledR}$. As propriedades foram selecionadas, considerando-se o número de propriedades existentes em cada município. Desta forma, obteve-se um número semelhante de propriedades amostradas entre os municípios.

O planejamento amostral para as unidades secundárias visou estimar o número mínimo de animais a serem examinados, dentro de cada propriedade, de forma a permitir a sua classificação como foco ou não para BoHV-1. O número de animais selecionados de cada rebanho foi igual em todas as propriedades, sendo amostrados 10 animais por propriedade, pois os rebanhos eram constituídos por até 99 fêmeas (Brasil, 2001).

Foi analisado um total de 920 amostras de soro de fêmeas leiteiras criadas em sistema intensivo de produção, sem sinais clínicos ou com a presença de sinais respiratórios e reprodutivos, estratificadas em três faixas etárias: < três anos (estrato-l), $20 \%$ das amostras, entre três a sete anos (estrato-II), $60 \%$ das amostras, e acima de sete anos (estrato-III), 20\% das amostras, provenientes de 92 rebanhos não vacinados contra o BoHV-1, conforme discriminado na Tabela 1.

Tabela 1. Distribuição das regionais com seus respectivos municípios, bem como o número de amostras/propriedade, Maranhão

\begin{tabular}{|c|c|c|c|}
\hline Regional & Municípios & $\begin{array}{c}\mathrm{N}^{\circ} \text { de } \\
\text { Propriedades }\end{array}$ & $\begin{array}{c}\mathrm{N}^{\circ} \text { de } \\
\text { Amostras }\end{array}$ \\
\hline \multirow{3}{*}{ Açailândia } & Açailândia & 4 & 40 \\
\hline & Cidelândia & 4 & 40 \\
\hline & São Francisco do Brejão & 4 & 40 \\
\hline \multirow{5}{*}{ Bacabal } & Bacabal & 4 & 40 \\
\hline & Lago Verde & 4 & 40 \\
\hline & Olho D’água das Cunhãs & 4 & 40 \\
\hline & São Luís Gonzaga & 4 & 40 \\
\hline & Bom Lugar & 4 & 40 \\
\hline \multirow{4}{*}{ Ilha de São Luís } & Paço Lumiar & 4 & 40 \\
\hline & São José de Ribamar & 4 & 40 \\
\hline & São Luís Gonzaga & 4 & 40 \\
\hline & Raposa & 4 & 40 \\
\hline \multirow{7}{*}{ Imperatriz } & Amarante & 4 & 40 \\
\hline & Imperatriz & 4 & 40 \\
\hline & João Lisboa & 4 & 40 \\
\hline & Lageado Novo & 4 & 40 \\
\hline & Porto Franco & 4 & 40 \\
\hline & São João do Paraíso & 4 & 40 \\
\hline & Senador La Roque & 4 & 40 \\
\hline \multirow{4}{*}{ Pedreiras } & Igarapé Grande & 4 & 40 \\
\hline & Bernardo do Mearim & 4 & 40 \\
\hline & Pedreiras & 4 & 40 \\
\hline & Trizidela do Vale & 4 & 40 \\
\hline Total & & 92 & 920 \\
\hline
\end{tabular}




\section{Colheita das amostras de sangue e dados epidemiológicos}

Os trabalhos a campo consistiram na colheita de sangue e preenchimento de um questionário epidemiológico. A colheita de sangue foi realizada por meio de punção da veia jugular utilizando agulha descartável estéril e tubo com vácuo, previamente identificado. As amostras de soro obtidas foram armazenadas em microtubos de plástico e congeladas a $-20^{\circ} \mathrm{C}$. O questionário epidemiológico foi aplicado em todas as propriedades selecionadas e teve por objetivo obter informações referentes ao manejo e ao estado sanitário dos animais.

\section{Teste sorológico}

A detecção qualitativa de anticorpos contra BoHV-1 foi realizada através da técnica de ELISA, utilizando kit comercial de ELISA indireto (CHEKIT IBR - SERO - Dr. BOMMELI AG/Liebefeld Bern - Swiss) no laboratório da divisão de antígenos do Instituto de Tecnologia do Paraná (TECPAR).

\section{Análise de dados}

As informações dos questionários, assim como o resultado da sorologia, foram armazenadas em um banco de dados utilizando o programa Microsoft Access $®$.

A propriedade foi considerada positiva (foco) para a presença do BoHV-1 se apresentasse pelo menos um animal reagente. As variáveis relacionadas no questionário epidemiológico permitiram o estudo de fatores de risco. Dentre elas, foram analisadas como possíveis fatores de risco: tipo de ordenha, reposição dos animais, produção de leite por vaca, assistência veterinária, reprodução, abortamentos, presença de caprinos/ ovinos, presença de suínos e sinais respiratórios.

Para o estudo da associação entre a soropositividade e as variáveis analisadas, foi feita a análise univariada, utilizando teste Exato de Fisher ou teste Qui-quadrado de independência, quando as condições para o teste Exato de Fischer não foram verificadas. O nível de significância utilizado foi de $5 \%$, com intervalos de confiabilidade de $95 \%$.

\section{Resultados e discussão}

No período e região estudados, foram verificados anticorpos para o BoHV-1 em 71,30\% $(n=656)$ dos animais analisados e em todas as propriedades estudadas. No estado do Maranhão, os trabalhos realizados anteriormente para a determinação da prevalência de anticorpos anti-BoHV-1 não foram conduzidos em número abrangente de amostras e, para alguns municípios, representa o primeiro relato desta infecção em bovinos leiteiros.

Com relação às cinco regionais avaliadas, foram obtidas prevalências de 68,12\% ( $n=109), 68,21 \% \quad(n=191), 71,67 \%$ $(n=86), 78,75 \%(n=126)$ e $72 \%(n=144)$ para as regionais da Ilha de São Luís, Imperatriz, Açailândia, Pedreiras e Bacabal, respectivamente. A presença de animais reagentes em todas as regionais e municípios indica que a infecção pelo BoHV-1 está amplamente distribuída no Maranhão.

A variação no percentual de animais reagentes para o vírus por propriedade variou de 20 a $100 \%$. Essa variação ocorreu tanto nas propriedades onde houve aquisição recente de animais, como naquelas que não receberam novos bovinos há pelo menos um ano, o que pode sugerir que a fonte de infecção deve provavelmente estar nos próprios rebanhos.
A análise univariada demonstrou que apenas a variável faixa etária apresentou associação estatística significativa $(P<0.005)$ ao risco de ocorrência da infecção (Tabela 2).

Quanto à faixa etária, foi encontrada maior prevalência de animais reagentes para o extrato II (3-7 anos), com 45,76\% $(n=362)$ de positividade e significância estatística $(P<0.005)$. Animais na idade adulta são mais comumente afetados pelo vírus, pois reflete a idade em que ocorre maior estresse em função da movimentação dos animais, maior grau de exposição ao vírus, provavelmente pela introdução de bovinos soropositivos nos lotes de produção, onde o animal portador está excretando o vírus em suas secreções. Além disso, na idade adulta, os animais estão no ápice das suas atividades produtivas e reprodutivas, sendo exigidos ao máximo (Chaves et al., 2010). As faixas etárias < três anos e > sete anos evidenciaram frequências de $9,57 \%$ e 5,54\%, respectivamente.

Foram observados coeficientes baixos de positividade para a variável sinais respiratórios $(0,86 \%)$ nas propriedades. Contudo, para esta variável nota-se elevada força de associação $(\mathrm{OR}=1.27)$, o que aumenta a probabilidade de ocorrência da infecção pelo BoHV-1 nestas propriedades. Em quadros clínicos que envolvem o sistema respiratório é importante diferenciar a infecção pelo BoHV-1 daquelas ocasionadas por outros patógenos que estão agrupados no Complexo Respiratório Bovino, como o vírus respiratório sincicial bovino (BRSV), vírus da diarreia viral bovina (BVDV), vírus parainfluenza tipo 3 (PI-3) e bactérias do gênero Pasteurella spp. (Obando et al., 1999).

Acerca do histórico de sinais reprodutivos nas propriedades estudadas, verificou-se que a prevalência de animais reagentes foi mais elevada entre os animais das propriedades que apresentavam histórico de alterações reprodutivas $(68,69 \%)$ e menores naquelas em que tal situação não ocorria $(2,60 \%)$, demonstrando que na região estudada esse vírus pode ser um dos agentes etiológicos e deve ser incluído no diagnóstico diferencial de problemas reprodutivos. Apesar desta variável não ter apresentado associação estatística significativa, animais de propriedades com este sinal clínico podem apresentar maior risco $(\mathrm{OR}=1.33)$ de apresentar o vírus como agente causador de abortamentos.

A variável "assistência veterinária" foi avaliada na análise dos riscos para o BoHV-1. No entanto, não foi apontada como tal. Verificou-se frequência mais elevada $(65,32 \%)$ nos animais procedentes das propriedades que não utilizavam assistência técnica, quando comparadas àquelas que a utilizavam $(5,97 \%)$. A falta de assistência médica veterinária pode ter refletido especialmente no diagnóstico e na ausência de implantação de programas de controle da infecção pelo BoHV-1.

É importante enfatizar que a infecção pelo BoHV-1 está disseminada no estado do Maranhão, conforme observado pelas prevalências apresentadas pelas regionais, municípios, propriedades e animais. E, diferentemente de infecções que cursam de forma aguda, esta, por ser ocasionada por um vírus que induz infecção latente, a soropositividade para o vírus representa a presença do animal portador e potencial disseminador do vírus no rebanho por toda a vida. Portanto, no geral, o estudo realizado mostrou que o BoHV-1 consiste em mais um problema sanitário adicional com o qual os produtores maranhenses têm de conviver.

Em consequência da latência do BoHV-1 e da alta prevalência de anticorpos verificado no estudo, é importante alertar sobre os mecanismos para o controle desta infecção. A prevenção 
Tabela 2: Fatores de risco para o herpesvírus bovino tipo 1 em fêmeas bovinas na bacia leiteira do estado do Maranhão

\begin{tabular}{|c|c|c|c|c|c|c|c|c|c|c|}
\hline & & \multicolumn{6}{|c|}{ Herpesvírus Bovino Tipo 1 (BoHV-1) } & \multirow{3}{*}{ *OR } & \multirow{3}{*}{ IC $95 \%$} & \multirow{3}{*}{ Valor de $\mathrm{P}$} \\
\hline \multirow{2}{*}{\multicolumn{2}{|c|}{ Variáveis }} & \multicolumn{2}{|c|}{ Reagentes } & \multicolumn{2}{|c|}{ Não Reagentes } & \multicolumn{2}{|c|}{ Total } & & & \\
\hline & & $\mathbf{N}$ & $\%$ & $\mathbf{N}$ & $\%$ & $\mathbf{N}$ & $\%$ & & & \\
\hline \multirow{3}{*}{ Faixa Etária } & $<3$ anos & 112 & 9,57 & 44 & 4,79 & 156 & 14,36 & \multirow{3}{*}{--} & \multirow{3}{*}{--} & \multirow{3}{*}{0.00} \\
\hline & 3 a 7 anos & 362 & 45,76 & 28 & 3,04 & 390 & 48,80 & & & \\
\hline & $<7$ anos & 44 & 4,79 & 9 & 0,97 & 53 & 5,76 & & & \\
\hline \multirow{2}{*}{ Aquisição de animais } & $\operatorname{Sim}$ & 641 & 69,67 & 103 & 11,19 & 744 & 80,86 & \multirow{2}{*}{0.41} & \multirow{2}{*}{$0.05 ; 3.17$} & \multirow{2}{*}{0.71} \\
\hline & Não & 15 & 1,60 & 1 & 0,10 & 16 & 1,70 & & & \\
\hline \multirow{3}{*}{ Aquisição de Animais } & Região & 611 & 66,41 & 102 & 11,08 & 712 & 77,49 & \multirow{3}{*}{--} & \multirow{3}{*}{--} & \multirow{3}{*}{0,08} \\
\hline & Estado & 72 & 7,82 & 21 & 2,28 & 93 & 10,10 & & & \\
\hline & Outros Estados & 46 & 5,00 & 11 & 11,95 & 57 & 16,95 & & & \\
\hline \multirow{2}{*}{$\begin{array}{c}\text { Presença de Ovinos/ } \\
\text { Caprinos }\end{array}$} & Sim & 147 & 15,97 & 29 & 3,15 & 176 & 19,12 & \multirow{2}{*}{0.74} & \multirow{2}{*}{$0.46 ; 1.19$} & \multirow{2}{*}{0.21} \\
\hline & Não & 509 & 55,32 & 75 & 8,15 & 584 & 63,47 & & & \\
\hline \multirow{2}{*}{ Presença de Suínos } & Sim & 151 & 16,41 & 29 & 3,15 & 180 & 19,56 & \multirow{2}{*}{0,77} & \multirow{2}{*}{$0.48 ; 1.23$} & \multirow{2}{*}{0.32} \\
\hline & Não & 505 & 54,89 & 75 & 8,15 & 580 & 63,04 & & & \\
\hline \multirow{3}{*}{ Produção de Leite/Vaca } & $1-5 L$ & 495 & 53,80 & 72 & 7,82 & 567 & 61,63 & \multirow{3}{*}{--} & & \\
\hline & $6-10 L$ & 154 & 16,73 & 32 & 3,47 & 186 & 20,21 & & -- & 0,17 \\
\hline & $>10 \mathrm{~L}$ & 7 & 0,76 & 0 & 0,00 & 7 & 0,76 & & & \\
\hline 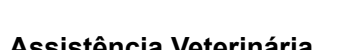 & Sim & 55 & 5,97 & 15 & 1,63 & 70 & 7,60 & 0.54 & $020 \cdot 100$ & $0 \Omega$ \\
\hline Assistencra vetermand & Não & 601 & 65,32 & 89 & 9,67 & 690 & 74,99 & 0.04 & $0.29,1.00$ & 0.00 \\
\hline & MN & 605 & 65,76 & 92 & 10,00 & 697 & 75,76 & & & \\
\hline Reprodução & IA & 34 & 3,96 & 10 & 1,08 & 44 & 4,77 & -- & -- & 0,18 \\
\hline & $\mathrm{MN}+\mathrm{IA}$ & 17 & 1,84 & 2 & 0,21 & 19 & 2,05 & & & \\
\hline Singic renrodutivos & Sim & 8 & 0,86 & 1 & 0,10 & 9 & 0,96 & 127 & $015 \cdot 102$ & 100 \\
\hline Sillats ieprociutivos & Não & 648 & 70,43 & 103 & 11,19 & 751 & 81,62 & 1.21 & $0.10,10.2$ & 1.00 \\
\hline & Sim & 632 & 68,69 & 99 & 10,76 & 731 & 79,45 & & & \\
\hline Abortamento & Não & 24 & 2,60 & 5 & 0,54 & 29 & 3,14 & 1.33 & $0.49 ; 3.56$ & $0.5 /$ \\
\hline
\end{tabular}

${ }^{{ }^{*} \mathrm{OR}=\text { Odds ratio }}$

de novas infecções pode ser realizada utilizando-se uma combinação entre a remoção gradual dos animais infectados, realização de quarentena no ingresso de novos bovinos na propriedade, exames sorológicos anuais, buscando impedir a reintrodução de animais infectados no rebanho e o uso de vacinas marcadas que permitam a diferenciação de animais vacinados e infectados, como sugerido por Quincozes (2007).

Os dados epidemiológicos obtidos neste estudo poderão auxiliar a planificação de estratégias de controle fundamentada nos resultados da análise dos fatores de risco associados à infecção pelo BoHV-1 no estado do Maranhão.
Com base nos resultados obtidos, pode-se concluir que: (i) a prevalência da infecção pelo herpesvírus bovino tipo 1 (BoHV-1) no estado do Maranhão foi elevada; (ii) apenas a variável faixa etária, entre 3 e 7 anos, apresentou associação estatística significativa associada à infecção pelo BoHV-1; (iii) com base nos dados de prevalência no rebanho bovino leiteiro do Maranhão, recomenda-se que sejam tomadas medidas de prevenção e controle, como remoção gradual de animais infectados, realização de quarentena ao ingresso de novos animais nas propriedades, realização de exames sorológicos e vacinações.

\section{Agradecimento}

Ao Instituto de Tecnologia do Paraná (TECPAR), em nome do Dr. Jorge Victor Bacila Agottani e da Dra Josiane Brodwikis, pelo suporte laboratorial necessário para a realização deste trabalho. 


\section{Referências}

ACKERMANN, M.; ENGELS, M. Pro and contra IBR-eradication. Veterinary Microbiology, v.113, n. 3/4, p. 293-302, 2006.

BARBOSA, A.C.V.C.; BRITO, W.M.E.D.; ALFAIA, B.T. Soroprevalência e fatores de risco para a infecção pelo herpesvírus bovino tipo 1 (BHV-1) no Estado de Goiás, Brasil. Ciência Rural, n. 35, v. 6, p. 1368-1373, 2005.

BRASIL. Ministério da Agricultura, Pecuária e Abastecimento. Programa Nacional de Controle e Erradicação da Brucelose e Tuberculose Animal (PNCEBT). Inquérito Soroepidemiológico da Brucelose: Manual de Procedimentos. Brasília: MAPA/SDA/DDA, 2001. 24 p.

CHAVES, N.P.; BEZERRA, D.C.; SOUSA, V.E de; SANTOS, H.P.; PEREIRA, $H$. de $M$. Frequência de anticorpos e fatores de risco para a infecção pelo vírus da diarreia viral bovina em fêmeas bovinas leiteiras não vacinadas na região Amazônica Maranhense, Brasil. Ciência Rural, v. 40, n. 6, p. 1448-1451, 2010.

CILENTO, M. do C.; PITUCO, E.M.; JORDÃO, R.S.; RIBEIRO, C.P.; FILHO, M.M.; MONTASSIER, H.J. Systemic and local antibodies induced by an experimental inactivated vaccine against bovine herpesvirus type. Ciência Rural, v. 41, n. 2, p. 307-313, 2011.

COLODEL, E.M.; NAKAZATO, L.; WEIBLEN, R.; MELLO, R.M.; SILVA, R.R.P.; SOUZA, M.A.; FILHO, J.A.O.; CARON, L. Meningoencefalite necrosante em bovinos causada por herpesvírus bovino no Estado de Mato Grosso, Brasil. Ciência Rural, v. 32, n. 2, p. 293-298, 2002.

FRANDOLOSO, R.; ANZILIERO, D.; SPAGNOLO, J. Prevalência de leucose enzoótica bovina, rinotraqueíte infecciosa bovina e neosporose bovina em 26 propriedades leiteiras da região nordeste do Rio Grande do Sul, Brasil. Ciência Animal Brasileira, v. 9, n. 4, p.1102-1106, 2008.

HOLZ, C.L.; CIBULSKI, S.P.; TEIXEIRA, T.F.; BATISTA, H.B.C.R.; CAMPOS, F.S.; SILVA, J.R.; VARELA, A.P.M.; CENCI, A.; FRANCO, A.C.; ROEHE, P.M. Soroprevalência de herpesvírus bovinos tipos 1 e/ou 5 no Estado do Rio Grande do Sul. Pesquisa Veterinária Brasileira, v. 29, n. 9, p. 767-773, 2009.

JONES, C. Herpes simplex virus type 1 and bovine herpesvírus 1 latency. Clinical Microbiology Review, v. 16, n. 1, p.79-95, 2003.

MUYLKENS, B.; THIRY, J.; KIRTEN, P.; SCHYNTS, F. Bovine herpesvirus 1 infection and bovine rhinotracheitis. Veterinary Research, v. 38, p. 181-209, 2007.
OBANDO, C.; BAULE, C.; PEDRIQUE, C.; VERACIERTA, C.; BELÁK, S.; MERZA, M.; MORENO-LOPEZ, J. Serological and molecular diagnosis of bovine viral diarrhoea virus and evidence of other viralinfections in dairy calves with respiratory disease inVenezuela. Acta Veterinaria Scandinavica, v. 40, n. 3, p. 253262, 1999.

QUINCOZES, C.G. Prevalência e fatores de risco associados às infecções pelos herpesvírus bovino tipos 1 e 5 (BHV-1 e 5) e pelo vírus da diarreia viral bovina (BVDV) nos rebanhos dos municípios de Santa Vitória do Palmar e Chuí. 117 f. Dissertação (Mestrado em Ciências) - Universidade Federal de Pelotas, Rio Grande do Sul, 2007.

RISSI, D.R.; RECH, R.R.; FLORES, E.F.; KOMMERS, G.D.; BARROS, C.S.L. Meningoencefalite por herpesvírus bovino-5. Pesquisa Veterinária Brasileira, v. 27, n. 7, p. 261-268, 2007.

SILVA, M.S.; BRUM, M.C.S.; WEIBLEN, R.; FLORES, E.F. Identificação e diferenciação de herpesvírus bovino tipos 1 e 5 isolados de amostras clínicas no centro-sul do Brasil, Argentina e Uruguai (1987-2006). Pesquisa Veterinária Brasileira, v. 27, n. 10, p. 403-408, 2007.

SOUSA, V.E.; BEZERRA, D.C.; CHAVES, N. P.; SANTOS, H.P.; PEREIRA, H.M. Frequência de anticorpos contra o herpesvírus bovino tipo 1 (BHV-1) em bovinos leiteiros não vacinados na bacia leiteira da ilha de São Luís-MA. Ciência Animal Brasileira, p. 491495, 2009, Suplemento 1.

STEUKERS, L.; VANDEKERCKHOVE, A.P.; BROECK, W.V. den; GLORIEUX, S.; NAUWYNCK, H.J.; Comparative analysis of replication characteristics of BoHV-1 subtypes in bovine respiratory and genital mucosa explants: a phylogenetic enlightenment. Veterinary Research, v. 42, n. 33, p. 1-11, 2011.

THRUSFIELD, M. 1995. Veterinary Epidemiology. 2. ed. Blackwell Science, Cambridge. 1995, 479 p.

VIEIRA, S.; BRITO, W.M.E.D.; SOUZA, W.J.; ALFAIA, B.T.; LINHARES, D.C.L. Anticorpos para o herpesvírus bovino 1(BHV1) em bovinos do Estado de Goiás. Ciência Animal Brasileira, v. 4, n. 2, p. 131-137, 2003.

VOGEL, F.S.; CARON, L.; FLORES, E.F.; WEIBLEN, R.; WINKELMANN, E.R.; MAYER, S.V.; BASTOS, R.G. 2003. Distribution of bovine herpesvirus type 5 DNA in the central nervous system of latently, experimentally infected calves. Journal Clinical Microbiology v. 41, n.10, p. 4512-4520, 2003. 